\title{
Multiple sclerosis and motor neurone disease: survival and how certified after death
}

\author{
FRANCES O'MALLEY, ${ }^{1}$ GEOFFREY DEAN ${ }^{2}$ AND MARTA ELIAN ${ }^{3}$ \\ From St James's Hospital, ${ }^{1}$ Dublin; The Medico-Social Research Board, ${ }^{2}$ and the Regional Centre for Neurology \\ and Neurosurgery, ${ }^{3}$ Oldchurch Hospital, Romford, Essex
}

SUMMARY This study assesses the outcome of a random sample of patients with multiple sclerosis (MS) and motor neurone disease (MND) selected from a previous study carried out between the years 1960 and 1972. Of the MND patients who are now dead, $20 \%$ of the women and $27 \%$ of the men lived longer than five years after hospitalised diagnosis, and two of these patients lived up to 19 years after diagnosis in hospital. Also, $10.7 \%$ of the random sample of MND patients were still alive in June 1985. Of the MS deaths $26.4 \%$ and of the MND deaths $20.4 \%$ did not have these respective conditions recorded on the death certificates.

A study to ascertain the prevalence of multiple sclerosis (MS) and motor neurone disease (MND) among the United Kingdom-born and various immigrant groups hospitalised in Greater London and in the West Midlands during the 13 years $1960-72$ has been previously undertaken. ${ }^{12}$ At this time a random sample of both the MS and MND records was coded so that the outcome of their disease could be ascertained.

\section{Method}

The random sample comprised 811 MS patients $(15 \%$ of the initial population) and 838 MND patients (37\% of the initial population) resident in Greater London and the West Midlands. A greater percentage of MND patients was chosen because they comprised the smaller initial group.

The final diagnosis of MS and MND on discharge had been made by the consultant neurologists on patients investigated as inpatients in London and Birmingham teaching hospitals. Copies of the summaries of the MND patients were obtained, and if there was any doubt about the diagnosis, in the relevant neurologist's opinion, the case was discarded. Most patients had been admitted more than once, and other conditions such as Charcot Marie Tooth disease and cervical spondylosis with myelopathy would have been excluded.

Each patient in the random sample was flagged at the National Health Service (NHS) Central Register, Southport, and after death the Central Register provided a copy of the death certificate (table 1). We
Table $1 M S$ and MND patients diagnosed in hospital 1960-72; June 1985

\begin{tabular}{|c|c|c|c|c|c|c|}
\hline \multirow[t]{2}{*}{ Patients } & \multicolumn{3}{|l|}{$M S$} & \multicolumn{3}{|l|}{$M N D$} \\
\hline & Male & Female & Total & Male & Female & Total \\
\hline Live & 140 & 262 & $402(49 \cdot 6 \%)$ & 31 & 9 & $40(10.4 \%)$ \\
\hline Dead & 144 & 144 & $288(35 \cdot 5 \%)$ & 151 & 114 & $265(69 \cdot 2 \%)$ \\
\hline $\begin{array}{l}\text { Embarked/ } \\
\text { psychiatric/ } \\
\text { armed forces }\end{array}$ & & 7 & $16(2 \cdot 0) \%$ & 2 & 0 & $2(0.5 \%)$ \\
\hline No trace & 37 & 68 & $\begin{array}{l}105(12.9 \%) \\
811\end{array}$ & 41 & 35 & $\begin{array}{l}76(19.8 \%) \\
383\end{array}$ \\
\hline
\end{tabular}

recorded, from the cards which had been prepared from the hospital records, the year of admission to hospital (this was not necessarily the first admission to hospital) and the age of each patient at the time of admission.

The name, age, sex, date of birth, date of death, primary and contributory cause of death, and age at death were available from the death certificates.

\section{Results}

\section{MULTIPLE SCLEROSIS}

Two hundred and eighty-eight MS patients (35.5\%) had died (June 1985), 144 women and 144 men (table 2). Overall, $45.5 \%$ of the death certificates had MS recorded in Part I of the certificate, that is as a direct cause, as an intervening antecedent cause or as an underlying antecedent cause of death. In Part II of the 
Table 2 Hospital diagnosed MS and MND patients: How death was reported on death certificate

\begin{tabular}{|c|c|c|c|c|c|c|}
\hline \multirow{2}{*}{$\begin{array}{l}\text { Death } \\
\text { certificate }\end{array}$} & \multicolumn{3}{|l|}{$M S$} & \multicolumn{3}{|c|}{$M N D$} \\
\hline & Male & Female & Overall & Male & Female & Overall \\
\hline Part I & $\begin{array}{l}42 \% \\
(61)\end{array}$ & $\begin{array}{l}49 \% \\
(70)\end{array}$ & $\begin{array}{l}45 \cdot 5 \% \\
(131)\end{array}$ & $\begin{array}{l}62 \% \\
(94)\end{array}$ & $\begin{array}{l}76 \% \\
(87)\end{array}$ & $\begin{array}{l}68 \cdot 3 \% \\
(181)\end{array}$ \\
\hline Part II & $\begin{array}{l}30 \% \\
(43)\end{array}$ & $\begin{array}{l}26 \% \\
(38)\end{array}$ & $\begin{array}{l}28 \% \\
(81)\end{array}$ & $\begin{array}{l}13 \% \\
(19)\end{array}$ & $\begin{array}{l}10 \% \\
(11)\end{array}$ & $\begin{array}{l}11 \cdot 3 \% \\
(30)\end{array}$ \\
\hline $\begin{array}{l}\text { Condition not } \\
\text { mentioned }\end{array}$ & $\begin{array}{l}28 \% \\
(40)\end{array}$ & $\begin{array}{l}25 \% \\
(36)\end{array}$ & $\begin{array}{l}26 \cdot 4 \% \\
(76)\end{array}$ & $\begin{array}{l}25 \% \\
(38)\end{array}$ & $\begin{array}{l}14 \% \\
(16)\end{array}$ & $\begin{array}{l}20.4 \% \\
(54)\end{array}$ \\
\hline Total number & (144) & (144) & (288) & (151) & (144) & (265) \\
\hline
\end{tabular}

Actual numbber in brackets

- As defined in the paper.

death certificate, $28 \%$ had MS mentioned as an "other significant condition contributing to the death but not related to the disease or condition causing it." Thus $26.4 \%$ did not have MS recorded on the death certificate.

Of the MS patients who have died, the mean age at diagnosis when they were hospitalised was 48.5 years for men and 47.4 years for women. The mean age at death for these patients was 55.9 years for men and 57.9 years for women. Thus the average survival of those who have died was 7.4 years for men and 10.5 years for women, after diagnosis in the hospitals whence the records were obtained.

The age at diagnosis compared with the number of years survived after diagnosis for the patients who are now dead was examined. This showed a very scattered distribution with no definable pattern. Most of the patients died before their normal life expectancy. However, one man lived longer than his normal life expectancy (according to Life Tables England and
Wales 1972-74). ${ }^{3}$ The pattern for the deceased female MS patients is very similar, none of the women reaching their normal life expectancy.

There were 402 live MS patients in the random sample (June 1985). Of these $34.8 \%$ were men and $65.2 \%$ were women. The mean age at diagnosis in hospital was $39 \cdot 1$ years for men and 39.9 for women. This is respectively 9.4 years and 7.5 years earlier than the corresponding age at diagnosis for the MS patients who are now dead. In the random sample, 105 of the MS patients could not be traced. This group was compared with the traced patients (both alive and dead) with respect to age and sex (table 3). There was no great difference between the traced and the untraced groups, and the traced group does not therefore represent a biased group.

\section{MOTOR NEURONE DISEASE}

Two hundred and sixty-five patients originally diagnosed as having one or other form of MND have died (151 men and 114 women). This represents $69 \cdot 2 \%$ of the initial MND population in the random sample compared with $35.5 \%$ of MS patients who have died.

Of these MND patients, $68.3 \%$ had the condition recorded on Part I of the death certificate, while $11.3 \%$ had it recorded on Part II. However, 20.4\% of those who have died did not have MND recorded on the death certificate.

The mean age at diagnosis in hospital for the MND patients who are now dead was 58.4 years for both men and women. This is about 10 years later than the mean age at which the MS patients were diagnosed in the hospitals in this study.

The mean age at death of these MND patients was 61.9 years for men and 61.4 years for women. Thus the average survival after hospitalised diagnosis was 3.5 years for men and 3 years for women.

Table 3 Comparison of traced with untraced patients

\begin{tabular}{|c|c|c|c|c|c|c|c|c|c|c|c|c|}
\hline & \multicolumn{6}{|c|}{ Traced } & & & & \multirow{2}{*}{\multicolumn{3}{|c|}{ Untraced }} \\
\hline & \multicolumn{3}{|l|}{ Dead } & \multicolumn{3}{|c|}{ Live (June 1985) } & \multicolumn{3}{|c|}{ Dead \& Alive (June 1985) } & & & \\
\hline & Male & Female & Total & Male & Female & Total & Male & Female & Total & Male & Female & Total \\
\hline \multicolumn{13}{|c|}{ Multiple sclerosis } \\
\hline $\begin{array}{l}\text { Sex number } \\
\%\end{array}$ & $\begin{array}{l}144 \\
50\end{array}$ & $\begin{array}{l}144 \\
50\end{array}$ & $\begin{array}{l}288 \\
100\end{array}$ & $\begin{array}{l}140 \\
34 \cdot 8\end{array}$ & $\begin{array}{l}262 \\
65 \cdot 2\end{array}$ & $\begin{array}{l}402 \\
100\end{array}$ & $\begin{array}{l}284 \\
41 \cdot 2\end{array}$ & $\begin{array}{l}406 \\
58 \cdot 8\end{array}$ & $\begin{array}{l}690 \\
100\end{array}$ & $\begin{array}{l}37 \\
35 \cdot 2\end{array}$ & $\begin{array}{l}68 \\
64 \cdot 8\end{array}$ & $\begin{array}{l}105 \\
100\end{array}$ \\
\hline $\begin{array}{l}\text { Mean age } \\
\text { at diagnosis }\end{array}$ & $48 \cdot 5$ & $47 \cdot 4$ & & $39 \cdot 1$ & $39 \cdot 9$ & & $43 \cdot 9$ & $42 \cdot 6$ & & $44 \cdot 0$ & $44 \cdot 1$ & \\
\hline \multicolumn{13}{|c|}{ Motor neurone disease } \\
\hline $\begin{array}{l}\text { Sex number } \\
\%\end{array}$ & $\begin{array}{l}151 \\
57.0\end{array}$ & $\begin{array}{l}114 \\
43.0\end{array}$ & $\begin{array}{l}265 \\
100\end{array}$ & $\begin{array}{l}31 \\
77 \cdot 5\end{array}$ & $\begin{array}{l}9 \\
22 \cdot 5\end{array}$ & $\begin{array}{l}40 \\
100\end{array}$ & $\begin{array}{l}182 \\
59 \cdot 7\end{array}$ & $\begin{array}{l}123 \\
40 \cdot 3\end{array}$ & $\begin{array}{l}305 \\
100\end{array}$ & $\begin{array}{l}41 \\
53 \cdot 9\end{array}$ & $\begin{array}{l}35 \\
46 \cdot 2\end{array}$ & $\begin{array}{l}76 \\
100\end{array}$ \\
\hline $\begin{array}{l}\text { Mean age } \\
\text { at diagnosis }\end{array}$ & 58.4 & 58.4 & & 51.5 & $48 \cdot 2$ & & 57.2 & 57.6 & & 55.6 & 57.0 & \\
\hline
\end{tabular}


The age at diagnosis versus the number of years survived after diagnosis for the MND patients differs greatly from that for the MS patients.

The majority of dead MND patients died within five years of hospitalised diagnosis $(73 \%$ of men and $80 \%$ of women). However, six MND men lived to their normal life expectancy. None of the women MND patients reached normal life expectancy.

Forty MND patients were still alive (June 1985). This comprises $10.4 \%$ of the random sample of MND patients, 31 men and 9 women. The mean age at diagnosis in hospital for these patients was 51.5 years for men and 48.2 years for women. Thus, these patients were 6.9 years and 10.2 years, respectively, younger at the time of diagnosis in hospital than the MND patients who are now dead. The mean years for life after diagnosis of the living patients was 16.4 years for men and 18.1 years for women (June 1985).

The case records of the 40 MND patients who are still alive were reviewed in order to study this group in greater detail. Twenty-one of the male patients' records are still available $(68 \%)$ and, of these, 19 had an exclusive diagnosis and a further 3 had been diagnosed initially as having MND, but the diagnosis was subsequently changed. Six of the female patients' records were still available and all of those had an exclusive diagnosis of MND

Seventy-six of the MND patients could not be traced (41 men and 35 women). This group of patients was compared with the traced MND patients (both alive and dead) with respect to age and sex (table 3). There was no great difference between the two groups. Therefore the traced group is not a biased sample and there is no reason to believe that it would be easier to trace the living than the dead through the Central Register.

\section{Discussion}

The mean age at hospitalisation for the MS patients who are still alive was $39 \cdot 1$ years for men and 39.9 years for women. The reported mean age at first diagnosis of MS is about 30 years, and many of our MS patients may have been diagnosed earlier than the age at hospitalisation reported here. In the West Midlands, unlike in London, many of the hospitals did not have a diagnostic index which would have made it possible to verify whether an admission was a first admission, and therefore the time of first diagnosis, or a subsequent admission.

Of the MS patients who died, the mean age at death was 55.9 years for men and 57.9 years for women. A study conducted in the Netherlands on reported deaths from MS between 1950 and 1968 showed similar figures. They found that the mean age at death was 56.9 years for men and $55 \cdot 2$ years for women. ${ }^{4}$
Of the MS patients who have died in this study, the average survival from the time of diagnosis was $7 \cdot 4$ years (men) and 10.5 years (women). Many studies have been carried out to assess survival, and there is wide variability. The early estimates of survival ranged from three to six years. ${ }^{5}$ Subsequent studies have estimated an average survival of between 13 and 20 years. ${ }^{68}$ In any series, the duration of the disease cannot be known accurately until all those in the study have died. Thus survival times derived from fatal cases are invariably too short. This is undoubtedly the case in our study.

The mean age at hospitalised diagnosis for the MND patients, both dead and alive (June 1985), was 57.2 years for men and 57.6 years for women (table 3 ). These figures agree with those from similar studies carried out in other countries. 9

The longevity of some of the MND patients is surprising. Of the patients who are now dead, $20 \%$ of the women and $27 \%$ of the men lived more than five years after hospitalised diagnosis, and, in fact, two of these patients lived up to 19 years after diagnosis in hospital. Also, 40 patients originally diagnosed as having MND are still alive (June 1985). At present it is believed that the duration from clinical onset to death for MND patients is seldom more than three years. ${ }^{10}$

The longevity of the MND patients in this studg may be explained in two ways. First, the initia diagnosis of MND may have been incorrect. Evidencest. to support this is the fact that six out of eight male MND patients who lived to or past their normal life expectancy did not have MND recorded on the death certificate. However, evidence against this explanation is that $62.5 \%$ of the MND patients who are still alive had a firm and unequivocal diagnosis of MND in the hospital records.

The second explanation is that the diagnosis of MND in the majority of these patients is correct, and the accepted 2-5 year survival of MND patients after diagnosis may not be accurate in all cases. Mulder and Howard found that $20 \%$ of patients with MND were still alive five years after diagnosis, ${ }^{11}$ and similar findings were reported by Mortara et al. ${ }^{12}$ Elian et al reported a longer survival (average 10.7 years) for those patients suffering from the progressive muscular atrophy form of MND. ${ }^{13}$ It would be interesting to know if the MND patients in this study who are still alive also have predominantly this form of the disease. Unfortunately, the type of MND by subtype is not recorded in the majority of the case records.

This study also shows how frequently MS and MND are mentioned on death certificates. Of the MS deaths $26.4 \%$ and of the MND deaths $20.4 \%$ did not have MS and MND respectively recorded on the death certificate. The MS figures are similar to those in a South African study (1955-64) where $29 \cdot 5 \%$ of MS 
patients who died did not have a diagnosis of MS on the death certificate. ${ }^{14}$

Leibowitz et af ${ }^{\beta 9}$ examined the cause of death in their MS patients. They found that in $58 \%$ of cases the cause was related to multiple sclerosis, the majority of these patients dying from infections consequent on the paralysed state.

Allen et $a^{15}$ reported on the general pathological findings in 120 necropsy proven cases of MS. They found that $74 \%$ of patients with MS died from complications of the disease, that is, pulmonary and renal infections. However, $26 \%$ died from apparently unrelated causes, such as deep venous thrombosis and pulmonary emboli, bacterial endocarditis, and peritonitis.

On reviewing the death certificates of those patients for whom MS or MND was not recorded, it was noted that $69.0 \%$ of the male MS patients died of cardiovascular causes and $31.0 \%$ of the women had various forms of carcinoma recorded as the primary cause of death. The main primary cause of death in this group for both the male and female MND patients was acute respiratory infections $\mathbf{( 4 2 . 9 \%}$ of the female deaths and $36.8 \%$ of the male deaths).

A further point of interest in these death certificates was that four patients ( 2 men and 2 women) who were originally diagnosed as having MND had MS recorded as the main cause of death. Also, one death certificate had both MND and MS recorded as primary causes of death, and as these two conditions are unlikely to co-exist in one patient, it is possible that the certifying doctor could not make up his mind as to which it was.

We would like to thank the staff in the hospital records departments of the Greater London and West Midlands hospitals involved in this study and the National Health Service Central Register, Southport. Our thanks are also due to Miss Hilda McLoughlin, who assisted us with research. The original study was supported by the Multiple Sclerosis Society of Great Britain and Northern Ireland.

\section{References}

${ }^{1}$ Dean G, Brady R, McLoughlin H, Elian M, Adelstein AM. Motor neurone disease and multiple sclerosis among immigrants to Britain. Br J Prev Soc Med 1977, 31, 3, 141-7.

2 Dean G, McLoughlin H, Brady R, Adelstein AM, TallettWilliams J. Multiple sclerosis among immigrants in Greater London. Br Med J. 1976, 1, 861-4.

${ }^{3}$ Life Tables, 1972-1974. Mortality Statistics England and Wales 1974. Series DHI, No.1. London: HMSO.

${ }^{4}$ Dassel $\mathrm{H}$. The mortality from multiple sclerosis in the Netherlands. Acta Nerol Scandinavica, 1973, 49, 659-74.

${ }^{5}$ Gowers WR. A manual of diseases of the nervous system, 2nd edition. London, vol.2, 553.

${ }^{6}$ Allison RS. Survival in disseminated sclerosis: a clinical study of a series of cases first seen 20 years ago. Brain, 1950, 103-120.

${ }^{7}$ Carter S, Sciarra D, Merritt $\mathbf{H H}$. The course of multiple sclerosis determined by autopsy proven cases. Research Publications of the Association for Research into Nervous and Mental Disease 1950, 28, 471-511.

${ }^{8}$ Leibowitz U, Kahana E, Jacobson SG, Alter M. The cause of death in multiple sclerosis. In: Leibowitz U (ed) Progress in multiple sclerosis. New York: Academic Press 1972; 196-209.

${ }^{9}$ Leibowitz U, Kahana E, Alter M. Survival and death in multiple sclerosis. Brain 1969, 92, 115-30.

${ }^{10}$ Wyngaarden B, Smith LH. Cecil textbook of medicine. Philadelphia, London, Toronto; WB Saunders Company, 1985.

11 Mulder DW, Howard FM. Patient resistance and prognosis in amyotrophic lateral sclerosis. Mayo Clin Proc, 1976, 51, 537-41.

12 Mortara P, Chio A, Rosso MG, Leone M, Schiffer D. Motor neurone disease in the Province of Turin, Italy, 1966-1980. J Neurol Sci 1984, 66: 165-73.

${ }^{13}$ Elian M, Artal M. Motor neurone disease in Israel. Lancet $1975,1,403-4$

${ }^{14}$ Dean G. Annual incidence, prevalence and mortality of multiple sclerosis in white South African-born and in white immigrants to South Africa. Br Med J 1976, 2, 724-30.

15 Allen IV, Millar JHD, Hutchinson MJ. General disease in 120 necropsy-proven cases of multiple sclerosis. Neuropath App Neurobiol 1978, 4, 279-84. 